\title{
Cavum septi pellucidi in first-episode schizophrenia and first-episode affective psychosis: an MRI study
}

\section{Citation}

Kasai K, McCarley RW, Salisbury DF, Onitsuka T, Demeo S, Yurgelun-Todd D, Kikinis R, Jolesz FA, Shenton ME. 2004. Cavum septi pellucidi in first-episode schizophrenia and first-episode affective psychosis: an MRI study. Schizophr Res 71, no. 1:65-76. doi:10.1016/ j.schres.2003.12.010

\section{Published Version}

doi:10.1016/j.schres.2003.12.010

\section{Permanent link}

http://nrs.harvard.edu/urn-3:HUL.InstRepos:28559581

\section{Terms of Use}

This article was downloaded from Harvard University's DASH repository, and is made available under the terms and conditions applicable to Other Posted Material, as set forth at http:// nrs.harvard.edu/urn-3:HUL.InstRepos:dash.current.terms-of-use\#LAA

\section{Share Your Story}

The Harvard community has made this article openly available.

Please share how this access benefits you. Submit a story.

Accessibility 


\title{
Cavum septi pellucidi in first-episode schizophrenia and first- episode affective psychosis: an MRI study
}

\author{
Kiyoto Kasai ${ }^{a, b}$, Robert W. McCarley ${ }^{a,}{ }^{*}$, Dean F. Salisburya,c, Toshiaki Onitsuka ${ }^{a}$, Susan \\ Demeo $^{a}$, Deborah Yurgelun-Todd ${ }^{d}$, Ron Kikinis ${ }^{e}$, Ferenc A. Jolesz ${ }^{e}$, and Martha E. \\ Shenton $a, e,{ }^{*}$ \\ aLaboratory of Neuroscience, Clinical Neuroscience Division, Department of Psychiatry, Boston VA \\ Healthcare System, Brockton Division, and Harvard Medical School, 940 Belmont St., Brockton, MA \\ 02301, USA \\ ${ }^{b}$ Department of Neuropsychiatry, Graduate School of Medicine, University of Tokyo, 7-3-1 Hongo, \\ Bunkyo, Tokyo 113-8655, Japan \\ ${ }^{\circ}$ Cognitive Neuroscience Laboratory, McLean Hospital, 115 Mill St., Belmont, MA 02478, USA \\ 'Brain Imaging Center, McLean Hospital, 115 Mill St., Belmont, MA 02478, USA \\ eSurgical Planning Laboratory, MRI Division, Brigham and Women's Hospital, Department of \\ Radiology, Harvard Medical School, 75 Francis St., Boston, MA 02115, USA
}

\begin{abstract}
A high prevalence of abnormal cavum septi pellucidi (CSP) in schizophrenia may reflect neurodevelopmental abnormalities in midline structures of the brain. The relationship, however, between abnormal CSP and clinical symptoms, and with abnormalities in other limbic structures remains unclear, as does the question of whether a similar abnormality is present in affective psychosis. Seventy-four patients at their first hospitalization, 33 with schizophrenia and 41 with affective (mainly manic) psychosis, and 56 healthy control subjects underwent high-spatialresolution magnetic resonance imaging (MRI). CSP on six slices or more on 0.9375-mm resampled coronal images was categorized as abnormal. The prevalence of abnormal CSP in both schizophrenic patients $(26.1 \%)$ and affective psychosis patients (18.2\%) was significantly higher than was observed in control subjects (8.2\%). In schizophrenic patients only, larger CSP was significantly associated with more severe thinking disturbance and smaller left parahippocampal gyrus gray matter volumes. While the relationships between CSP ratings and clinical symptoms did not significantly differ between the two psychosis groups as assessed by the comparison of regression slopes, the association with limbic volumes appeared to be specific to schizophrenic patients. These results suggest that psychosis associated with schizophrenia and affective disorder share, at least to some extent, neurodevelopmental abnormalities involving midline structures and associated psychopathological consequences. However, the association between abnormal CSP and limbic systems may be more specific to schizophrenia.
\end{abstract}

\footnotetext{
(C) 2004 Elsevier B.V. All rights reserved.

*Corresponding authors. Department of Psychiatry (116A), Boston VA Healthcare System, Brockton Division, Harvard Medical School, 940 Belmont St., VAMC Brockton, MA 02301, USA. Tel.: +1-508-583-4500x3723 or x2473; fax: +1-508-586-0894. robert_mccarley@hms.harvard.edu (R.W. McCarley), martha_shenton@hms.harvard.edu (M.E. Shenton).
} 


\section{Keywords}

Cavum septum pellucidum; Magnetic resonance imaging; Neurodevelopment; Schizophrenia; Affective disorder; First-episode

\section{Introduction}

Schizophrenia has been characterized, at least in part, as a neurodevelopmental disorder (e.g., Akil and Weinberger, 2000), although a possible progressive process in cortical regions has recently been suggested by longitudinal structural magnetic resonance imaging (MRI) studies (Gur et al., 1998; Kasai et al., 2003; Lieberman et al., 2001; Mathalon et al., 2001).

Interest in a neurodevelopmental hypothesis stems primarily from etiological (e.g., maternal viral infections, obstetric complications), phenotypic (e.g., minor physical anomalies, premorbid intellectual, motor, and behavioral abnormalities), and neuropathological (e.g., presence of structural brain changes at first-episode, absence of gliosis in postmortem brains, gray matter heterotopias) evidence. One reliable indicator, from a neuropathological perspective, has been provided by in vivo MRI studies, where a higher-than-normal prevalence of cavum septi pellucidi (CSP) (Degreef et al., 1992; DeLisi et al., 1993; Rajarethinam et al., 2001; Shioiri et al., 1996) and/or large (abnormal) CSP (Kwon et al., 1998; Nopoulos et al., 1997; Shioiri et al., 1996) has been observed in patients with schizophrenia.

The CSP is the space between the two leaflets of the septum pellucidum (Hopkins and Lewis, 2000). In normal development, fusion of the septi pellucidi occurs within 3-6 months of birth due to rapid growth of midline structures of the brain including the corpus callosum and limbic system structures such as the amygdala, hippocampus, and parahippocampal gyrus. Incomplete fusion results in the persistence of a CSP, which reflects possible neurodevelopmental abnormalities of these midline and limbic structures (Rakic and Yakovlev, 1968; Sarwar, 1989; Shaw and Alvord, 1969). Particularly noteworthy, however, are recent high-spatialresolution MRI studies (Fukuzako et al., 1996; Hagino et al., 2001; Kwon et al., 1998; Nopoulos et al., 1997; Rajarethinam et al., 2001) that tend to report a higher prevalence of CSP (38.0$84.8 \%$ ) in normal adults than previous MRI studies with lower spatial resolution (1.1-29.8\%) (Degreef et al., 1992; DeLisi et al., 1993; Jurjus et al., 1993; Shioiri et al., 1996). These more recent in vivo MRI studies suggest that a small CSP is likely a normal variant.

Of further note, out of nine independent research studies investigating the prevalence and/or qualifying the rate of abnormal CSP in patients with schizophrenia compared with normal subjects using MRI (Degreef et al., 1992; DeLisi et al., 1993; Fukuzako et al., 1996; Hagino et al., 2001; Jurjus et al., 1993; Kwon et al., 1998; Nopoulos et al., 1997; Rajarethinam et al., 2001; Shioiri et al., 1996), six reported positive findings (Degreef et al., 1992; DeLisi et al., 1993; Kwon et al., 1998; Nopoulos et al., 1997; Rajarethinam et al., 2001; Shioiri et al., 1996). It is not clear, however, what the relationship of CSP findings is to clinical characteristics and abnormalities in limbic structures in patients with schizophrenia. Here, we note that of the four studies that assessed relationships between CSP and clinical symptoms (Jurjus et al., 1993; Kirkpatrick et al., 1997; Kwon et al., 1998; Nopoulos et al., 2000), only Kirkpatrick et al. (1997) reported an association with more severe formal thought disorder. Additionally, associations with lower general intelligence (Nopoulos et al., 2000) and poorer prognosis (Fukuzako et al., 1996) have been reported. For relationships with brain morphology, an association with a left-sided volume reduction and a left-less-than-right asymmetry of the temporal lobe (Nopoulos et al., 1996), and with reduced volumes of bilateral posterior amygdale-hippocampal complex (Kwon et al., 1998) have been reported, whereas DeLisi et 
al. (1993) failed to find significant associations with corpus callosum areas, or ventricular or temporal lobe volumes.

A comparison with affective psychosis is also a critical issue, since whether psychosis associated with schizophrenia and affective disorder represent manifestations of different disorders or the same disorder is an important but unresolved question in psychiatry. Indeed, neurodevelopmental aspects of affective disorder have also been suggested in the literature (Bearden et al., 2001; Nasrallah, 1991). However, findings from previous MRI studies of CSP in affective disorder have been mixed (Jurjus et al., 1993; Shioiri et al., 1996) (reviewed and discussed in detail in Discussion), and these studies did not specifically evaluate psychotic patients with affective disorder except for our preliminary observation of 16 patients with psychotic affective disorder (Kwon et al., 1998). Our previous findings of gray matter reduction of left posterior amygdala-hippocampal complex, common to first-episode psychotic patients with schizophrenia and affective disorder (Hirayasu et al., 1998), together with a possible relationship between neurodevelopment of septum and the limbic structures, bear on the interesting question of whether or not both psychoses share neurodevelopmental abnormalities in midline structures and associated limbic systems. Moreover, the comparison of patterns in the relationship of CSP to clinical and morphological indices between schizophrenic and affective psychosis patients may also be important to characterize similarities and differences in the etiology and pathophysiology of psychosis associated with the two disorders.

In our previous study (Kwon et al., 1998), we reported: (1) patients with schizophrenia (firstepisode and chronic schizophrenia combined) have increased prevalence of abnormally large CSP (evaluated using 1.5-mm-thickness MR slices) compared with control subjects, (2) firstepisode patients with affective psychosis have a rate of large CSP intermediate between subjects with schizophrenia and controls, but the sample size was relatively small $(N=16)$, (3) no relationship between symptom ratings and CSP in subjects with chronic or first-episode patients with schizophrenia, but again the sample size was small ( $N=15$ for both chronics and first-episodes), (4), significant relationships in chronic schizophrenia only $(N=15)$ between larger CSP size and lower gray matter volume of posterior amygdala-hippocampal complex. Accordingly, in the current study we quantified CSP using high-spatial-resolution MRI (approximately 1-mm voxels in resampled slices) in an extended sample of first-episode patients with schizophrenia and affective psychosis, and in healthy control subjects.

Correlational analyses were also performed between CSP ratings and clinical symptoms and medial temporal lobe gray matter volumes.

\section{Methods}

\subsection{Subjects}

Participating in the study were 74 first-episode patients with psychosis, 33 (5 women) with schizophrenia and 41 (10 women) with affective psychosis, and 56 (12 women) healthy control subjects. This study is an extension of our previous study of CSP (Kwon et al., 1998), and subjects in the current study included $N=15$ patients with first-episode schizophrenia, $N=16$ patients with first-episode affective psychosis, and $N=18$ healthy controls from Kwon et al. study.

Age, gender distribution, and handedness (the Edinburgh Inventory; Oldfield, 1971) were not significantly different among groups (Table 1). Socioeconomic status (SES) of subjects was measured using the Hollingshead two-factor index (Hollingshead, 1965). Schizophrenic patients showed significantly lower SES than affective psychosis patients and control subjects (Table 1). Parental SES was slightly different among groups, but not significantly different between any combination of groups based on post hoc analyses (Table 1). 
The affective psychosis patient group (all psychotic) included 37 bipolar disorder patients in a manic phase and 4 major depressive (unipolar) disorder patients. The statistical conclusions reported below remained the same when only the manic affective psychosis patients were included. Patients were recruited from inpatients at McLean Hospital, a private psychiatric hospital affiliated with Harvard Medical School. Control subjects were recruited through newspaper advertisement. Our local Institutional Review Board approved this study. After a complete description of the study, written informed consent was obtained from all participants.

The protocols for diagnosis and clinical evaluations have been described in detail in previous studies (Salisbury et al., 1998; Hirayasu et al., 1998, 1999, 2000, 2001; Lee et al., 2002). Briefly, patients and control subjects met criteria for age (18-55 years), IQ above 75, right-handedness, and negative history for seizures, for head trauma with loss of consciousness, for neurologic disorder, and for any lifetime history of alcohol or other drug dependence. Control subjects were screened using the Structured Clinical Interview for DSM-III-R-Non-Patient Edition (SCID-NP) (Spitzer et al., 1990a) by trained interviewers (DFS, MES). No control subject had an Axis-I or II psychiatric disorder or a first-degree relative with Axis-I psychiatric disorder.

The same trained interviewers (DFS, MES) diagnosed patients based on the DSM-IV criteria, using the SCID interview (Spitzer et al., 1990b), and information from the medical records. Diagnoses were confirmed at follow-up interview. Consistent with the literature (e.g., DeLisi et al., 1997; Salisbury et al., 1998; Hirayasu et al., 1998, 1999, 2000, 2001; Lee et al., 2002; Lieberman et al., 2001), first-episode was operationally defined as the first psychiatric hospitalization. Median duration of psychotropic medication prior to MRI was short (Table 1). At the time of the first scan, patients were variously receiving: no medication ( 2 schizophrenic, 5 affective); neuroleptics [typical $(9,18)$, atypical $(17,15)$, or both $(4,3)]$; mood stabilizers [lithium $(3,8)$, valproate $(6,14)$, or both $(0,2)]$; while typical/atypical neuroleptic status for one schizophrenic subject was unknown due to enrollment in a double-blinded Olanzapine/ Haloperidol cross-over protocol. Medication dose and age at first medication use were not significantly different between the two psychosis groups (Table 1).

Clinical evaluations included the Mini-Mental State Examination (MMSE) (Folstein et al., 1975), the information and digits-forward and -backward subscales of the Wechsler Adult Intelligence Scale-Revised (WAIS-R) (Wechsler, 1981), the Global Assessment Scale (GAS) (Endicott et al., 1976), and the total and four syndrome factors scores of the Brief Psychiatric Rating Scale (BPRS) (Overall and Gorham, 1962, Overall et al., 1967). Of note, scores on MMSE, WAIS-R subscales, GAS, and total BPRS were not significantly different between the two psychosis groups (Table 1).

\subsection{MRI image acquisition and processing}

MR images were acquired with a 1.5-T scanner (GE Medical Systems, Milwaukee). The MR acquisition protocol and the post-processing of images have elsewhere been described in detail (Wible et al., 1995). Briefly, a 1.5-mm-thick coronal series of contiguous SPGR images (repetition time $=35 \mathrm{~ms}$, echo time $=5 \mathrm{~ms}$, voxel dimensions $=0.9375 \times 0.9375 \times 1.5 \mathrm{~mm}$ ) was used for quantifying CSP. An anisotropic diffusion filter $(k=13$ for SPGR and 90 for proton/T2 images, iteration $=3$ ) (Gerig et al., 1992) was applied to the images to reduce noise prior to processing each set of scans. Images were aligned using the line between the anterior and posterior commissures (AC-PC) and the sagittal sulcus to correct head tilt, and were also resampled to make voxels isotropic (sides measured $0.9375 \mathrm{~mm}$ ) (Hirayasu et al., 2000; Lee et al., 2002). 


\subsection{CSP measures}

For quantifying the CSP, the number of slices containing CSP (Fig. 1) was counted on a series of coronal images without knowledge of diagnosis. When a certain slice appeared to have a partial volume effect, we considered the slice to contain CSP. This definition may be too inclusive, but we regard this to be objective to enable a reliable measurement. Since the images were 0.9375 -mm thick without gaps, the multiplication of the rating by 0.9375 was a reflection of the actual anterior-to-posterior length of the cavum, although partial volume effects renders this an approximation only. For example, a CSP with a rating of 6 would be approximately 5.6 mm long.

From the results of recent high-spatial-resolution MRI studies (Fukuzako et al., 1996; Hagino et al., 2001; Kwon et al., 1998; Nopoulos et al., 1997; Rajarethinam et al., 2001) that report high prevalence of CSP (38.0-84.8\%) in adults, it is clear that the presence of a very small CSP may have no pathological significance. Therefore, it was necessary to distinguish CSP that were considered to be larger than the normal variant CSP. For this determination we used criteria similar to that of Kwon et al. (1998), where CSP on one to five slices was categorized as normal, and on six or more slices $(5.6 \mathrm{~mm}$ ) as abnormal (see Fig. 2 for three-dimensional presentation of abnormal CSP). The rationale for this categorization was based on several references that indicate the best estimate of normal variant cavum is that of 1-4 $\mathrm{mm}$ (Barr and Kiernan, 1988; Martin, 1989; Roberts et al., 1987; Sarwar, 1989; Shaw and Alvord, 1969).

For interrater reliability, three raters (K.K., T.O., and S.D.), blinded to group membership, independently rated CSP for 50 cases. The intraclass correlation coefficient was 0.98 .

\subsection{Statistical analyses}

2.4.1. Group differences in CSP-The prevalence of abnormal CSP was compared between each combination of two diagnostic groups using the goodness of fit test. For comparison purpose, the same statistical procedure was applied to the data where the subjects with complete fusion of septum $(\mathrm{CSP}=0)$ were included in the analysis.

2.4.2. Correlations with clinical measures-Spearman's rho was used in planned analyses of the correlations between CSP ratings and four syndrome factor scores of the BPRS separately for each psychosis group. The number of subjects for whom BPRS scores were available was $N=32$ for the schizophrenia group and $N=38$ for the affective group. Here, we used $p<0.05$ as the cut-off for reporting statistical significance. In addition, we used one-tailed tests since negative correlations between CSP ratings and severity of clinical symptoms were predicted. We did not use BPRS individual items (18 items) in order to avoid type I errors. We then tested whether there were differences between groups in the relationship between CSP ratings and clinical measures using the test for comparison of two regression slopes. Here, we used $p<0.05$ as the cut-off for reporting statistical significance.

Spearman's rho was also used in exploratory analyses of the correlations between ratings of CSP and other clinical measures including MMSE, WAIS-R subscales, and GAS, separately for each diagnostic group (GAS scores were only applicable for the two psychosis group), where we used Bonferroni correction for multiple correlations.

2.4.3. Correlations with limbic structure volumes-Spearman's rho was calculated for planned analyses of the correlations between CSP ratings and medial temporal lobe gray matter volumes (left and right anterior amygdala-hippocampal complex [mostly amygdala], left and right posterior amygdale-hippocampal complex [mostly hippocampus], and left and right parahippocampal gyri) (Hirayasu et al., 1998), separately for each diagnostic group. The number of subjects for whom regions of interest (ROIs) measures were available was $N=17$ 
for the schizophrenia group, $N=16$ for the affective group, and $N=18$ for the control group. Here, we considered any correlation to be significant if the values for both absolute and relative ([absolute volume/intracranial content $] \times 100$ ) volumes reached $p<0.05$. Here, we did not use Bonferroni correction, since these analyses were planned and significant correlations between CSP ratings and volumes of hippocampus and/or parahippocampal gyrus only in psychotic groups were predicted. In addition, we used one-tailed tests since negative correlations between CSP ratings and volume measures were predicted. The rationale for these decisions was as follows: (1) in normal neurodevelopment, the fusion of CSP is associated with the growth of limbic structures; (2) previous findings in the literature suggest that abnormalities in limbic structures, including hippocampal formation and parahippocampal gyrus, may be related to psychosis (e.g., Bogerts, 1997); and, (3) our previous study (Kwon et al., 1998) found a significant negative correlation between CSP ratings and hippocampal volumes in patients with chronic schizophrenia. We then tested whether there were differences between groups for the relationship between CSP ratings and volume measures using the test for comparison of two regression slopes in each combination of the three diagnostic groups. Here, we used $p<0.05$ as the cut-off for reporting statistical significance.

The detailed methods for measurements of medial temporal lobe ROIs are provided elsewhere (Hirayasu et al., 1998). Briefly, the amygdala-hippocampal complex and parahippocampal gyrus were outlined manually on a Sun workstation. The most anterior slice used for the amygdala-hippocampal complex was the one in which the white matter tract linking the temporal lobe with the rest of the brain (temporal stem) could be seen. The most posterior slice was the last appearance of fibers of the crux of the fornix. The posterior segment of the amygdala/hippocampal complex began with the first appearance of the mammillary bodies. The parahippocampal gyrus (non-subicular portions) was defined laterally by the collateral sulcus and a demarcation line drawn across the narrow portion of the gyral isthmus at the deepest portion of the collateral sulcus. Medial temporal lobe structures, rather than neocortical areas [i.e., STG (Hirayasu et al., 1998), Heschl's gyrus and planum temporale (Hirayasu et al., 2000), prefrontal neocortex (Hirayasu et al., 2001), fusiform gyrus (Lee et al., 2002) as reported in our previous studies] were selected, since an association between CSP and these limbic structures was predicted.

\section{Results}

Age, SES, parental SES, handedness, age of first medication, duration of medication, or dose of medication did not correlate with the number of slices containing CSP in any group (rho = -0.19 to $0.30 ; p=0.091$ to 0.88 ). There were also no gender differences in the prevalence of CSP or abnormal CSP for any group, nor were there gender differences when the diagnoses were collapsed.

\subsection{Group differences in CSP}

The CSP was present ( 1 slice or more) for $N=23 / 33$ (69.7\%) of schizophrenic patients, $N=$ $33 / 41(80.5 \%)$ of affective psychosis patients, and $N=49 / 56(87.5 \%)$ of control subjects. The prevalence of CSP was not significantly different among groups (chi-square $=4.24, d f=2, p$ $=0.12$ ).

We found that abnormal CSP was present in $26.1 \%$ of schizophrenic patients, $18.2 \%$ of affective psychosis patients, and $8.2 \%$ of control subjects (Table 2). The schizophrenic patients showed significantly higher prevalence than control subjects (the goodness of fit test: chisquare $=9.86, d f=1, p=0.002$ ). Affective psychosis patients also showed significantly higher prevalence than control subjects (chi-square $=4.42, d f=1, p=0.036$ ), while the two psychosis group did not differ significantly in the prevalence of abnormal CSP (chi-square $=1.07, d f=$ $1, p=0.30$ ). When we included subjects who have complete fusion of septum, the statistical 
conclusion did not change (schizophrenia vs. control: chi-square $=6.06, d f=1, p=0.014$; affective vs. control: chi-square $=3.47, d f=1, p=0.063$; schizophrenia vs. affective: chisquare $=0.347, d f=1, p=0.56$ ).

\subsection{Correlations with clinical measures}

Schizophrenic patients showed a positive correlation between the number of slices containing CSP and scores for thinking disturbance factor of the BPRS (comprised of items of conceptual disorganization, hallucinatory behavior, and unusual thought content) (rho $=0.365, N=32$, $p=0.040$; regression line: $Y=6.46+0.446 X)$. There was no significant correlation between CSP ratings and thinking disturbance factor scores ( $\mathrm{rho}=0.027, N=38, p=0.87$; regression line: $Y=7.06-0.0469 X)$ for affective psychosis patients. The comparison of regression slopes, however, did not show significant difference between the two psychosis groups $(t[66]=1.49$, $p>0.1$, two-tailed). After Bonferroni correction for multiple correlations, there were no significant correlations between ratings of CSP and other clinical measures including MMSE, WAIS-R subscales, and GAS, separately for each diagnostic group (GAS scores were only applicable for the two psychosis groups) (Table 3).

\subsection{Correlations with limbic structure volumes}

There was a significantly negative correlation between CSP ratings and left parahippocampal gyrus gray matter volume in the schizophrenia group (rho $=-0.462, N=17, p=0.031$; regression line: $Y=2.45-0.0650 X$ ), but not in the affective group (rho $=0.039, N=16, p=$ 0.44 ; regression line: $Y=1.93+0.0332 X$ ) or the control group ( rho $=0.353, N=18, p=0.076$; regression line: $Y=1.83+0.143 X$ ). Based on the comparison of regression slopes, there was a significant difference between schizophrenic patients and affective psychosis patients $(t[29]$ $=-2.12, p<0.05$, two-tailed), and between schizophrenic patients and control subjects $(t[31]$ $=-2.84, p<0.01$, two-tailed), but not between affective psychosis patients and control subjects $(t[30]=-0.37, p>0.6$, two-tailed $)$, in the relationship between CSP ratings and left parahippocampal gyrus gray matter volume.

\section{Discussion}

The results of the current study can be summarized as follows: (1) schizophrenic patients and affective psychosis patients did not significantly differ in the prevalence of abnormal CSP, and both groups had significantly higher prevalence than control subjects; (2) larger CSP was associated with more severe thinking disturbance factor scores of the BPRS and smaller left parahippocampal gyrus gray matter volumes in schizophrenic patients; (3) schizophrenic and affective psychosis patients were not significantly different in the relationship of CSP with symptoms, but the relationships with parahippocampal volumes were specific to schizophrenic patients. The high prevalence of abnormal CSP in both psychoses and a lack of specificity in the association with positive symptoms suggest that schizophrenia and affective psychosis may share, at least to a certain extent, neurodevelopmental abnormalities and associated psychopathological consequences. On the other hand, neurodevelopmental abnormalities involving midline structures and associated limbic systems appeared to be more specific to schizophrenic patients compared with affective psychosis and healthy subjects.

We found a high prevalence of presence of CSP for all groups (69.7\% of schizophrenic patients, $80.5 \%$ of affective psychosis patients, and $87.5 \%$ of control subjects). These findings are consistent with recent high-resolution MRI studies (Fukuzako et al., 1996; Hagino et al., 2001; Kwon et al., 1998; Nopoulos et al., 1997; Rajarethinam et al., 2001), and further suggest that a small CSP is a normal anatomical variant. In contrast, the prevalence of abnormal CSP (approximately $6 \mathrm{~mm}$ or longer) was higher for first-episode schizophrenic patients than for 
the control subjects, in line with recent studies (Kwon et al., 1998; Nopoulos et al., 1997; Shioiri et al., 1996).

For associations with clinical symptoms, schizophrenic patients showed a positive correlation between the CSP ratings and scores for thinking disturbance factor of the BPRS. To our knowledge, four studies (Jurjus et al., 1993; Kirkpatrick et al., 1997; Kwon et al., 1998; Nopoulos et al., 2000) have assessed relationships between CSP abnormalities and clinical symptoms, but only one study reported significant associations with more severe formal thought disorder (Kirkpatrick et al., 1997). Thus, the current study confirms an association between CSP and positive symptoms in patients with schizophrenia. Although clinical symptoms may be unstable at first-hospitalization, patients may show potentially higher symptom severity especially for positive symptoms compared with remitted or chronic status, resulting in a broader distribution of data. The use of 1.0-mm resampled slices may also have an advantage in yielding broadly distributed data for CSP ratings compared with the previous three studies using 1.5 to $5 \mathrm{~mm}$ slices. The septum pellucidi is a component of the limbic system and serves as an important relay station connecting the hypothalamic autonomic system to hippocampus, amygdala, habenula, and brainstem reticular formation (Sarwar, 1989).

Structural and functional abnormalities in the limbic system including hippocampal formation and parahippocampal gyrus are thought to be associated with positive symptoms of schizophrenia (reviewed in Bogerts, 1997). The disturbance in this system in the perinatal neurodevelopment may thus form a potential basis for developing positive symptoms in patients with schizophrenia. However, here we note that the CSP itself is associated with a wide range of developmental conditions related to cognitive impairment that do not usually result in manifest psychosis (e.g., Bodensteiner et al., 1998; Kim and Peterson, 2003). In schizophrenia, early insults in the perinatal period and later mal-maturation perhaps predominantly in frontotemporal neocortex may, at least in part, form a basis for frank psychosis. Abnormal CSP and associated limbic structures may thus be understood as an index of the severity of neurodevelopmental insult that, if coupled with mal-maturation of frontotemporal neocortex in the peri-onset period, may form a basis for the manifestation of psychosis.

Partially consistent with the above interpretation, we found a significant correlation between CSP ratings and gray matter volumes of the left parahippocampal gyrus, a part of the limbic system. Moreover, this association appeared to be more specific to schizophrenia compared with affective psychosis and control groups based on the comparison of regression slopes. However, we failed to replicate the previous finding of a significant association between CSP ratings and bilateral posterior amygdala-hippocampal (mostly hippocampus) gray matter volumes in patients with chronic schizophrenia (Kwon et al., 1998). The reason for the discrepancy is unclear, since using first-episode patients has theoretically fewer confounds of chronicity of illness and the effects of chronic treatment, which should thus have an advantage in exploring the association between abnormalities of neurodevelopmental origin and ROI volumes. One possible explanation may be differences in the clinical characteristics of the two samples. For example, in the Kwon study, some of the most severe cases of schizophrenia were included, and these individuals had an average of 15 years illness duration. In our sample, it is not known which of the first-episode cases of schizophrenia will go on to have such a poor outcome.

Our earlier study (Kwon et al., 1998) evaluated CSP in 30 patients with schizophrenia (15 chronic, 15 first-episode), 16 first-episode patients with affective psychosis, and 46 control subjects (21 subjects with schizotypal personality disorder were also included). In that study, the prevalence of abnormal CSP in affective psychosis was intermediate (20\%) between schizophrenic patients (30.4\%) and control subjects (10.3\%), with no significant difference from either group. In the present study, with larger sample sizes, the prevalence of abnormal 
CSP for affective psychosis patients was shown to be significantly higher than that for control subjects. Moreover, based on analyses using the comparison of regression slopes, the relationship of abnormal CSP to abnormalities in clinical presentation were also not significantly different between schizophrenic and affective psychosis patients. Thus, the present study indicates that psychosis associated with schizophrenia and affective disorder may share an abnormal neurodevelopment of the brain midline structures and associated psychopathological outcome. These results are in line with those of Shioiri et al. (1996), who reported significantly higher prevalence of CSP in bipolar patients (7.2\%) compared with control subjects (1.1\%), but not significantly different from schizophrenic patients (17.5\%). In contrast, Jurjus et al. (1993) reported that affective patients (bipolar and schizoaffective disorder) were not different in the prevalence of CSP (10.0\%) from normal controls (18.9\%), and showed significantly lower prevalence than schizophrenic patients (25.4\%). However, since these previous studies did not assess psychotic patients with affective disorder only, direct comparison with the present study should be regarded with caution.

Some methodological issues in our study need to be commented upon. First, we need to consider the issue of statistical power regarding our results of lack of significant difference between schizophrenia and affective psychosis in the clinical relationships with CSP. Although the required $N$ was fairly large for the correlation with BPRS ( $N=120$ for both groups) to be significantly different between groups, the results of similarities in the clinical correlations should be confirmed by studies with larger sample size. Second, the results of our correlational analyses should be interpreted with caution since there were multiple statistical comparisons thus being liable to type I errors, and the $N$ for analyses of associations with volume measures was relatively small. Third, we need to comment on the fact that our first-episode psychosis sample included some later-onset subjects aged above 30 at first-hospitalization ( 9 out of 74 psychosis subjects). However, the rate of the presence of abnormal CSP did not differ significantly between the younger (10/65) and older (2/9) subjects (Fisher's exact test, $p=$ 0.63 ). Therefore, this sample characteristic did not appear to affect the conclusion of the present study.

In conclusion, the similarities in the high prevalence of abnormal CSP and its association with positive symptoms suggest the importance of CSP as an index of neurodevelopmental abnormalities and its psychopathological consequences in the pathophysiology of psychosis associated with schizophrenia and affective disorder. On the other hand, associations between neurodevelopmental abnormalities involving midline structures and limbic systems may be specific to schizophrenia.

\section{Acknowledgments}

This study was supported, in part, by the Department of Veterans Affairs Merit Awards (RWM and MES), a Middleton Award from the Department of Veterans Affairs (RWM), grants from the National Institute of Health (K02 MH 01110 [MES] and R01 MH 50747 [MES], and R01 MH 40799 [RWM], R01 RR 11747 [RK], and P41 PR13218 [FAJ]), the Welfide Medicinal Research Foundation, Japan (KK), and the Uehara Memorial Foundation, Japan (KK). The authors gratefully acknowledge the administrative support of Marie Fairbanks and the research assistant support of Magdalena Spencer and Margaret Fagan.

\section{References}

Akil, M.; Weinberger, DR. Neuropathology and the neurodevelopmental model. In: Harrison, PJ.; Roberts, GW., editors. The Neuropathology of Schizophrenia. New York: Oxford Univ. Press; 2000. p. 189-212.

Barr, M.; Kiernan, J. The Human Nervous System: An Anatomical Viewpoint. Philadelphia: J.B. Lippincott; 1988.

Bearden CE, Hoffman KM, Cannon TD. The neuropsychology and neuroanatomy of bipolar affective disorder: a critical review. Bipolar Disord 2001;3:106-150. [PubMed: 11465675] 
Bodensteiner JB, Schaefer GB, Craft JM. Cavum septi pellucidi and cavum vergae in normal and developmentally delayed populations. J. Child Neurol 1998;13:120-121. [PubMed: 9535237]

Bogerts B. The temporolimbic system theory of positive schizophrenic symptoms. Schizophr. Bull 1997;23:423-435. [PubMed: 9327507]

Degreef G, Bogerts B, Falkai P, Greve B, Lantos G, Ashtari M, Lieberman J. Increased prevalence of the cavum septum pellucidum in magnetic resonance scans and post-mortem brains of schizophrenic patients. Psychiatry Res. Neuroimaging 1992;45:1-13.

DeLisi LE, Hoff AL, Kushner M, Degreef G. Increased prevalence of cavum septum pellucidum in schizophrenia. Psychiatry Res. Neuroimaging 1993;50:193-199.

DeLisi LE, Sakuma M, Tew W, Kushner M, Hoff AL, Grimson R. Schizophrenia as a chronic active brain process: a study of progressive brain structural change subsequent to the onset of schizophrenia. Psychiatry Res. Neuroimaging 1997;74:129-140.

Endicott J, Spitzer RL, Fleiss JL, Cohen J. The global assessment scale. A procedure for measuring overall severity of psychiatric disturbance. Arch. Gen. Psychiatry 1976;33:766-771. [PubMed: 938196]

Folstein MF, Folstein SE, McHugh PR. "Mini-Mental State": a practical method for grading the cognitive state of patients for the clinician. J. Psychiatr. Res 1975;12:189-198. [PubMed: 1202204]

Fukuzako T, Fukuzako H, Kodama S, Hashiguchi T, Takigawa M. Cavum septum pellucidum in schizophrenia: a magnetic resonance imaging study. Psychiatry Clin. Neurosci 1996;50:125-128. [PubMed: 9201757]

Gerig G, Kubler O, Kikinis R, Jolesz FA. Nonlinear anisotropic filtering of MRI data. IEEE Trans. Med. Imag 1992;11:221-232.

Gur RE, Cowell P, Turetsky BI, Gallacher F, Cannon T, Bilker W, Gur RC. A follow-up magnetic resonance imaging study of schizophrenia. Relationship of neuroanatomical changes to clinical and neurobehavioral measures. Arch. Gen. Psychiatry 1998;55:145-152. [PubMed: 9477928]

Hagino H, Suzuki M, Kurokawa K, Mori K, Nohara S, Takahashi T, Yamashita I, Yotsutsuji T, Kurachi M, Seto H. Magnetic resonance imaging study of the cavum septi pellucidi in patients with schizophrenia. Am. J. Psychiatry 2001;158:1717-1719. [PubMed: 11579008]

Hirayasu Y, Shenton ME, Salisbury DF, Dickey CC, Fisher IA, Mazzoni P, Kisler T, Aarakaki H, Kwon JS, Anderson JE, Yurgelun-Todd D, Tohen M, McCarley RW. Lower left temporal lobe MR volumes in patients with first-episode schizophrenia compared with psychotic patients with first-episode affective disorder and normal subjects. Am. J. Psychiatry 1998;155:1384-1391. [PubMed: 9766770]

Hirayasu Y, Shenton ME, Salisbury DF, Kwon JS, Wible CG, Fischer IA, Yurgelun-Todd D, Zarate C, Kikinis R, Jolesz FA, McCarley RW. Subgenual cingulate cortex volume in first-episode psychosis. Am. J. Psychiatry 1999;156:1091-1093. [PubMed: 10401458]

Hirayasu Y, McCarley RW, Salisbury DF, Tanaka S, Kwon JS, Frumin M, Snyderman D, YurgelunTodd D, Kikinis R, Jolesz FA, Shenton ME. Planum temporale and Heschl gyrus volume reduction in schizophrenia. Arch. Gen. Psychiatry 2000;57:692-699. [PubMed: 10891040]

Hirayasu Y, Tanaka S, Shenton ME, Salisbury DF, DeSantis MA, Levitt JJ, Wible C, Yurgelun-Todd D, Kikinis R, Jolesz FA, McCarley RW. Prefrontal gray matter volume reduction in first-episode schizophrenia. Cereb. Cortex 2001;11:374-381. [PubMed: 11278200]

Hollingshead, AB. Two Factor Index of Social Position. New Haven: Yale Univ. Press; 1965.

Hopkins, R.; Lewis, S. Structural imaging findings and macroscopic pathology. In: Harrison, PJ.; Roberts, GW., editors. The Neuropathology of Schizophrenia. New York: Oxford Univ. Press; 2000. p. 5-56.

Jurjus G, Nasrallah HA, Olson SC, Schwarzkopf SB. Cavum septum pellucidum in schizophrenia, affective disorder, and healthy controls: a magnetic resonance imaging study. Psychol. Med 1993;23:319-322. [PubMed: 8332648]

Kasai K, Shenton ME, Salisbury DF, Hirayasu Y, Lee CU, Ciszewski AA, Yurgelun-Todd DA, Kikinis R, Jolesz FA, McCarley RW. Progressive decrease of left superior temporal gyrus gray matter volume in first-episode schizophrenia. Am. J. Psychiatry 2003;160:156-164. [PubMed: 12505815]

Kim KJ, Peterson BS. Cavum septi pellucidi in Tourette syndrome. Biol. Psychiatry 2003;54:76-85. [PubMed: 12842311]

Kirkpatrick B, Litman D, Kim JW, Vladar K, Breier A, Buchanan RW. Failure of fusion of the septum pellucidum and the heterogeneity of schizophrenia. J. of Nerv. Ment. Dis 1997;185:639-641. [PubMed: 9345255] 
Kwon JS, Shenton ME, Hirayasu Y, Salisbury DF, Fischer IA, Dickey CC, Yurgelun-Todd D, Tohen M, Kikinis R, Jolesz FA, McCarley RW. MRI study of cavum septi pellucidi in schizophrenia, affective disorder, and schizotypal personality disorder. Am. J. Psychiatry 1998;155:509-515. [PubMed: 9545997]

Lee CU, Shenton ME, Salisbury DF, Kasai K, Onitsuka T, Dickey CC, Yurgelun-Todd D, Kikinis R, Jolesz FA, McCarley RW. Fusiform gyrus volume reduction in first-episode schizophrenia: an MRI Study. Arch. Gen. Psychiatry 2002;59:775-781. [PubMed: 12215076]

Lieberman JA, Chakos M, Wu H, Alvir J, Hoffman E, Robinson D, Bilder R. Longitudinal study of brain morphology in first episode schizophrenia. Biol. Psychiatry 2001;49:487-499. [PubMed: 11257234]

Martin, J. Neuroanatomy: Text and Atlas. New York: Elsevier; 1989.

Mathalon DH, Sullivan EV, Lim KO, Pfefferbaum A. Progressive brain volume changes and the clinical course of schizophrenia in men: a longitudinal magnetic resonance imaging study. Arch. Gen. Psychiatry 2001;58:148-157. [PubMed: 11177116]

Nasrallah HA. Neurodevelopmental aspects of bipolar affective disorder. Biol. Psychiatry 1991;29:1-2. [PubMed: 2001443]

Nopoulos P, Swayze V, Andreasen NC. Pattern of brain morphology in patients with schizophrenia and large cavum septi pellucidi. J. Neuropsychiatry Clin. Neurosci 1996;8:147-152. [PubMed: 9081549]

Nopoulos P, Swayze V, Flaum M, Ehrhardt JC, Yuh WTC, Andreasen NC. Cavum septi pellucidi in normals and patients with schizophrenia as detected by magnetic resonance imaging. Biol. Psychiatry 1997;41:1102-1108. [PubMed: 9146821]

Nopoulos P, Krie A, Andreasen NC. Enlarged cavum septi pellucidi in patients with schizophrenia: clinical and cognitive correlates. J. Neuropsychiatry Clin. Neurosci 2000;12:344-349. [PubMed: 10956567]

Oldfield RC. The assessment and analysis of handedness: the Edinburgh Inventory. Neuropsychologia 1971;9:97-113. [PubMed: 5146491]

Overall JE, Gorham DR. The brief psychiatric rating scale. Psychol. Rep 1962;10:799-812.

Overall JE, Hollister LE, Pichot P. Major psychiatric disorders: a four-dimensional model. Arch. Gen. Psychiatry 1967;16:146-151. [PubMed: 6019329]

Rajarethinam R, Miedler J, DeQuardo J, Smet CI, Brunberg J, Kirbat R, Tandon R. Prevalence of cavum septum pellucidum in schizophrenia studied with MRI. Schizophr. Res 2001;48:201-205. [PubMed: 11295373]

Rakic P, Yakovlev PI. Development of corpus callosum and cavum septi in man. J. Comp. Neurol 1968;132:355-362.

Roberts, M.; Hanaway, J.; Morest, D. Atlas of the Human Brain in Section. 2nd ed.. Philadelphia: Lea \& Febiger; 1987.

Salisbury DF, Shenton ME, Sherwood AR, Fischer IA, Yurgelun-Todd DA, Tohen M, McCarley RW. First-episode schizophrenic psychosis differs from first-episode affective psychosis and controls in P300 amplitude over left temporal lobe. Arch. Gen. Psychiatry 1998;55:173-180. [PubMed: 9477932]

Sarwar M. The septum pellucidum: normal and abnormal. Am. J. Neuroradiol 1989;10:989-1005. [PubMed: 2505543]

Shaw CM, Alvord EC. Cavum septi pellucidi et vergae: their normal and pathological state. Brain 1969;92:213-224. [PubMed: 5774029]

Shioiri T, Oshitani Y, Kato T, Murashita J, Hamakawa H, Inubushi T, Nagata T, Takahashi S. Prevalence of cavum septum pellucidum detected by MRI in patients with bipolar disorder, major depression and schizophrenia. Psychol. Med 1996;26:431-434. [PubMed: 8685300]

Spitzer, RL.; Williams, JBW.; Gibbson, M.; First, M. The Structured Clinical Interview for DSM-III-RNon-Patient Edition (SCID-NP). Washington, DC: American Psychiatric Association; 1990a.

Spitzer, RL.; Williams, JBW.; Gibbson, M.; First, M. The Structured Clinical Interview for DSM-III-R (SCID). Washington, DC: American Psychiatric Association; 1990b.

Wechsler, D. Wechsler Adult Intelligence Scale-Revised. New York: Harcourt Brace Jovanovich; 1981. 
Wible CG, Shenton ME, Hokama H, Kikinis R, Jolesz FA, Metcalf D, McCarley RW. Prefrontal cortex and schizophrenia: a quantitative magnetic resonance imaging study. Arch. Gen. Psychiatry 1995;52:279-288. [PubMed: 7702444] 

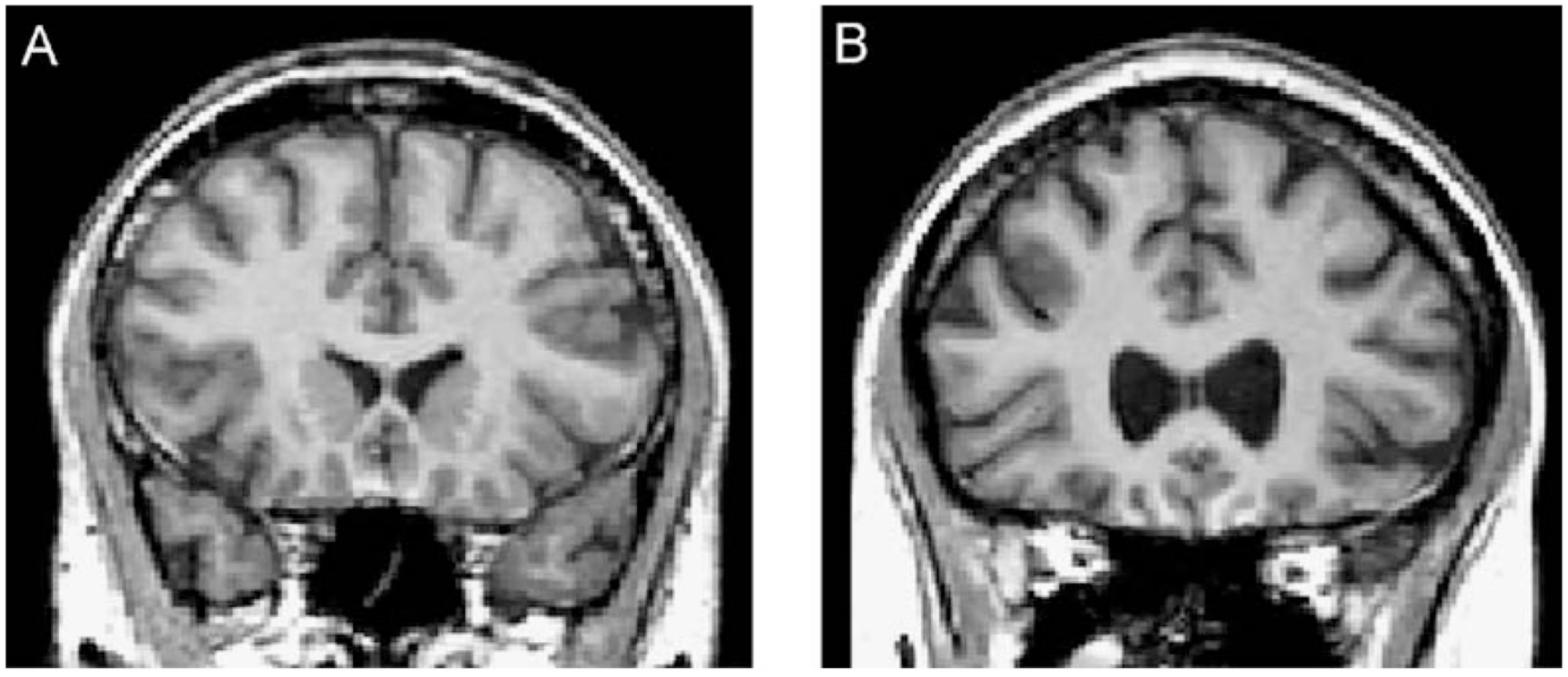

Fig. 1.

MR images of cavum septi pellucidi. Panel A: a normal subject showing no cavum septi pellucidi. Panel B: a first-episode patient with schizophrenia showing abnormal cavum septi pellucidi on the coronal plane. 


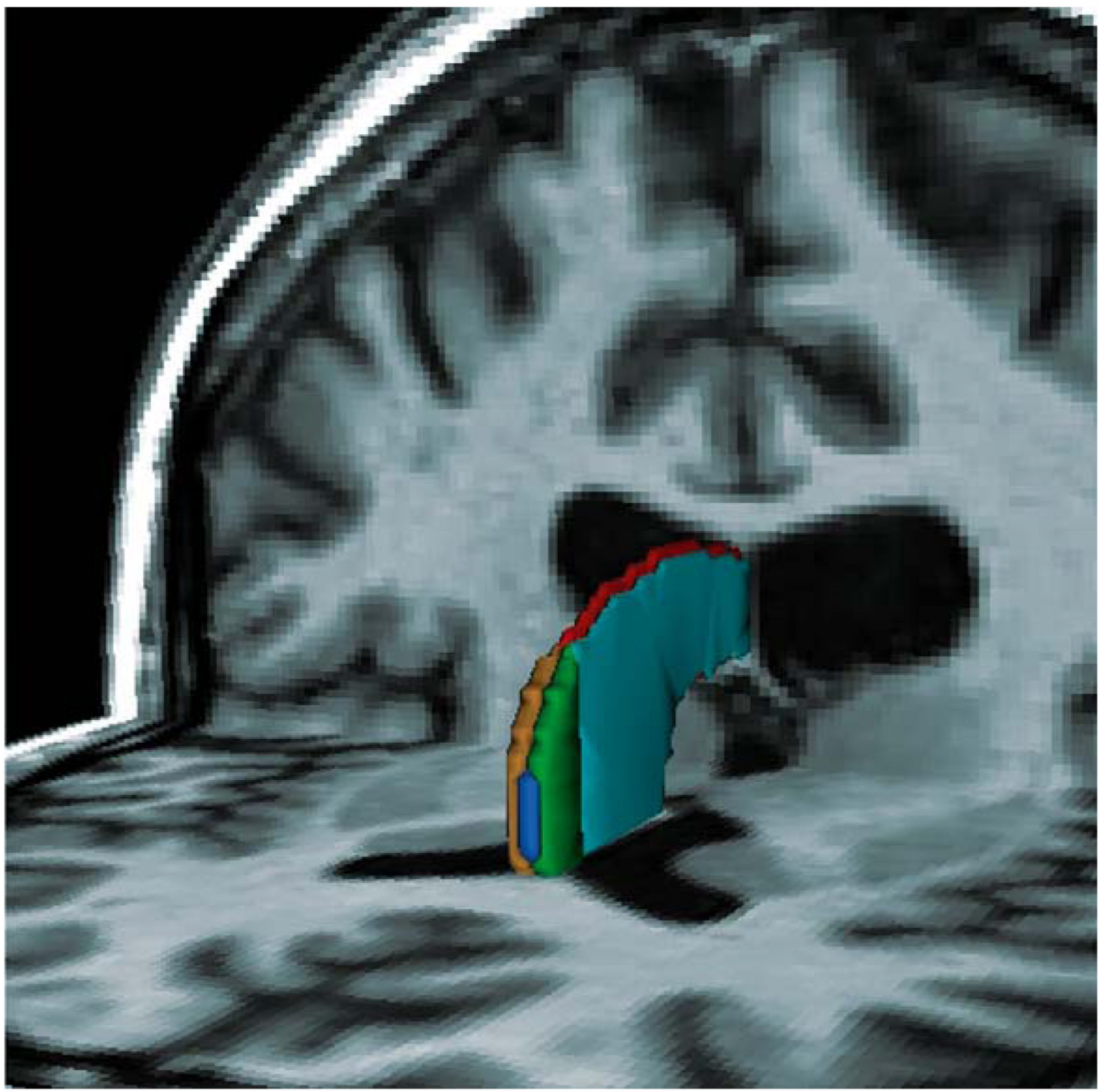

Fig. 2.

Three-dimensional reconstruction of a large cavum septi pellucidi superimposed on the axial and coronal planes. The MRI image presented here is from the same patient with schizophrenia as in Panel B of Fig. 1. The CSF content of the large cavum can be seen between the two leaflets of the septi pellucidi and is labeled blue. The anterior portions of the leaflets, which are separated to form the cavum between the septi pellucidi, are green on subject left and gold on subject right. The posterior portions of the leaflets, where they fuse, are light blue on subject left and red on subject right. 


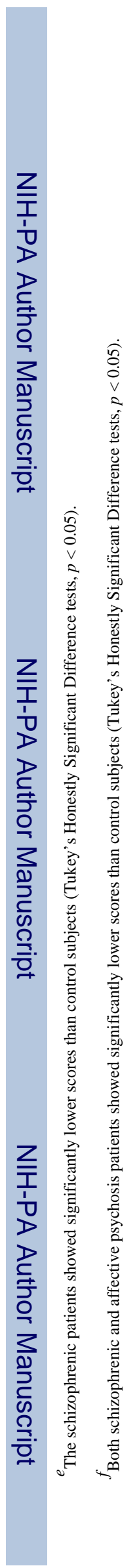




\section{Table 2}

Frequency of normal and abnormal cavum septi pellucidi in first-episode patients with schizophrenia, firstepisode patients with affective psychosis, and healthy control subjects

\begin{tabular}{|c|c|c|c|c|}
\hline \multirow[t]{3}{*}{ Group } & \multicolumn{4}{|c|}{ Cavum septi pellucidi } \\
\hline & \multicolumn{2}{|l|}{$\begin{array}{l}\text { Normal } \\
\text { (1-5 slices) }\end{array}$} & \multicolumn{2}{|c|}{$\begin{array}{l}\text { Abnormal } \\
\text { ( } 6 \text { slices or more) }\end{array}$} \\
\hline & $N$ & $\%$ & $N$ & $\%$ \\
\hline $\begin{array}{l}\text { Schizophrenic } \\
\text { patients }\end{array}$ & 17 & 73.9 & 6 & $26.1^{a}$ \\
\hline $\begin{array}{l}\text { Affective } \\
\text { psychosis } \\
\text { patients }\end{array}$ & 27 & 81.8 & 6 & $18.2^{b}$ \\
\hline $\begin{array}{l}\text { Control } \\
\text { subjects }\end{array}$ & 45 & 91.8 & 4 & 8.2 \\
\hline
\end{tabular}

\footnotetext{
${ }^{a}$ Significantly higher than expected in control subjects (the goodness of fit test: chi-square $=9.86, d f=1, p=0.002$ ).

${ }^{b}$ Significantly higher than expected in control subjects (the goodness of fit test: chi-square $=4.42, d f=1, p=0.036$ ).
} 
Table 3

Correlation between cavum septi pellucidi ratings and clinical and volume measures

\begin{tabular}{|c|c|c|c|}
\hline \multirow[t]{2}{*}{ Variables } & \multicolumn{3}{|c|}{ Spearman's rho ${ }^{a}$} \\
\hline & $\begin{array}{l}\text { Schizophrenic } \\
\text { patients }\end{array}$ & $\begin{array}{l}\text { Affective } \\
\text { patients }\end{array}$ & $\begin{array}{l}\text { Control } \\
\text { subjects }\end{array}$ \\
\hline \multicolumn{4}{|c|}{ Clinical measure (BPRS factor) X CSP rating } \\
\hline Thinking disturbance & $\begin{array}{l}0.365^{b} \\
(N=32)\end{array}$ & $\begin{array}{l}0.027 \\
(N=38)\end{array}$ & - \\
\hline $\begin{array}{l}\text { Hostility- } \\
\text { suspiciousness }\end{array}$ & $\begin{array}{l}-0.058 \\
(N=32)\end{array}$ & $\begin{array}{l}-0.047 \\
(N=38)\end{array}$ & - \\
\hline $\begin{array}{l}\text { Withdrawal- } \\
\text { retardation }\end{array}$ & $\begin{array}{l}0.227 \\
(N=32)\end{array}$ & $\begin{array}{l}-0.082 \\
(N=38)\end{array}$ & - \\
\hline Anxiety-depression & $\begin{array}{l}0.020 \\
(N=32)\end{array}$ & $\begin{array}{l}-0.067 \\
(N=38)\end{array}$ & - \\
\hline \multicolumn{4}{|c|}{ Limbic gray matter volume $X$ CSP rating } \\
\hline Left amygdala & $\begin{array}{l}0.040 \\
(N=17)\end{array}$ & $\begin{array}{l}0.181 \\
(N=16)\end{array}$ & $\begin{array}{l}0.563^{c} \\
(N=18)\end{array}$ \\
\hline Right amygdala & $\begin{array}{l}0.227 \\
(N=17)\end{array}$ & $\begin{array}{l}0.169 \\
(N=16)\end{array}$ & $\begin{array}{l}0.204 \\
(N=18)\end{array}$ \\
\hline Left hippocampus & $\begin{array}{l}0.468 \\
(N=17)\end{array}$ & $\begin{array}{l}0.226 \\
(\mathrm{~N}=16)\end{array}$ & $\begin{array}{l}0.342 \\
(\mathrm{~N}=18)\end{array}$ \\
\hline Right hippocampus & $\begin{array}{l}0.173 \\
(N=17)\end{array}$ & $\begin{array}{l}0.355 \\
(N=16)\end{array}$ & $\begin{array}{l}0.512^{c} \\
(N=18)\end{array}$ \\
\hline $\begin{array}{l}\text { Left parahippocampal } \\
\text { gyrus }\end{array}$ & $\begin{array}{l}-0.462^{d} \\
(N=17)\end{array}$ & $\begin{array}{l}0.039 \\
(N=16)\end{array}$ & $\begin{array}{l}0.353 \\
(N=18)\end{array}$ \\
\hline $\begin{array}{l}\text { Right parahippocampal } \\
\text { gyrus }\end{array}$ & $\begin{array}{l}-0.034 \\
(N=17)\end{array}$ & $\begin{array}{l}-0.279 \\
(N=16)\end{array}$ & $\begin{array}{l}0.609^{c} \\
(N=18)\end{array}$ \\
\hline
\end{tabular}

BPRS, Brief Psychiatric Rating Scale; ellipses, data not applicable.

${ }^{a}$ The number of subjects varied according to the availability of data.

${ }^{b}$ Statistically significant $(p=0.020$, one-tailed).

${ }^{c}$ Statistically significant positive correlations. However, the values reported here are for absolute volumes, and none of them remained significant when relative volumes were used. Therefore, these correlations were not considered important, since they may simply have been the result of differences in overall brain/head size.

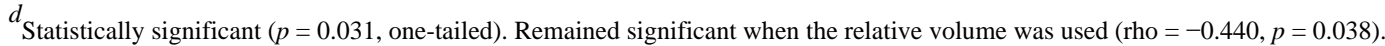

